\title{
The Fourth Meaning in Life: With a Discussion of What Viktor E. Frankl Calls Meaning
}

\author{
Kenjiro Uemura \\ The Open University of Japan
}

\begin{abstract}
The purpose of this paper is, first of all, to show what V. E. Frankl calls meanings rooted in three values: creative values, experiential values, and attitudinal values. Creative values are what one finds by creating a work or doing a deed. Experiential values are realized by experiencing something or encountering someone. Attitudinal values are what a person discovers by the attitude she/he takes toward unavoidable suffering. The author points out that these three kinds of values have something in common: connectedness or relationship. Creative values (e.g., an artistic masterpiece) show the worker's connectedness with the work accomplished. Experiential values also stand for the relationship between, say, a person and natural beauty. Frankl describes a person's attitudinal values by stating "He may turn a personal tragedy into a triumph." In short, we can say that attitudinal values indicate relationship between the sufferer and suffering itself. The author states the core of Frankl's three values is the aforementioned connectedness or relationship. In other words, what Frankl calls meanings indicates manifestation of connectedness or relationship in the form of creations, experiences, and attitudes. However, in this paper, the author insists that even if Frankl's three kinds of values are not realized, there is another value to realize beyond Frankl's three kinds of values, which is coexistence. Within this context, Frankl fails to mention cases where one cannot find meaning in life by a deed or work they does, an experience they encounter, or an attitude they takes in the midst of suffering. The three types of meanings in life need a skill, a chance, and/or ego-strength. We can discover meaning in life just by being together, and the author proposes the fourth meaning in life, or coexistent values. It can be defined as "values realized by having meaningful relationships or togetherness with others." Careful analysis of Frankl' writings shows connectedness aspects of logotherapy, in addition to meaningfulness aspects of logotherapy which are necessarily referred to by researchers on Frankl. The fourth meaning in life could shed new light on the understanding of logotherapy.
\end{abstract}

Keywords: Viktor E. Frankl, creative values, experiential values, attitudinal values, coexistent values, logotherapy

\section{Introduction}

Dr. Daniel P. Sulmasy proposes the bi-psychosocio-spiritual model for the care of patients at the end of life and tells the effect that human persons are intrinsically spiritual and they are beings in relationship $(2002,25)$.

Kenjiro Uemura, Graduate School of The Open University of Japan, Kumamoto Study Center Student, Master of Law, Certified Social Worker, Japan; main research fields: Spiritual Care Studies, Clinical Psychology, and Social Work.

Acknowledgements: Both in tangible and spiritual ways, the author is indebted to two supervisors. One is Dr. Tsutomu Okabe, Director of Kumamoto Study Center, The Open University of Japan, an expert of Aristotelian studies. The other is Visiting Professor of the Study Center, Terry Laskowski who helped the author with editing. Without their assistance, this paper cannot come into being. 
This statement indicates the holistic paradigm of care in that it gets into the biological, psychological, social, and spiritual dimension of human beings. Nowadays holistic or four-dimensional approach to the care of dying people is indispensable to those engaged in helping dying patients. As a matter of fact, we can see the elements of holistic care in the Frankl's logotherapy which enjoys much reputation as the Third Viennese School of Psychotherapy.

Although he does not state explicitly "holistic" paradigm, his holistic view of a person is expressed in these statements. He says, "But we must ask ourselves... whether a break-through into another dimension [other than dimensions of Freud's psychoanalysis and Adler's individual psychology] may not be permissible, or even requisite in order to yield a true picture of the total psycho-physico-spiritual entity which is man" (1980, 9 , brackets are mine). In particular, he emphasizes the spiritual aspects of human beings in logotherapy, while referring to it as a psychotherapy $(1988,99)$. Frankl's main concerns are to help patients find their meaning in life. That is, logotherapy is nothing other than spiritual care, largely because many clinicians and researchers would agree that finding meaning in life is sine qua non in spiritual caregiving.

Actually logotherapy is employed not only as a psychiatric helping technique, but also as an art of caring for those who have terminally ill and dementia. For example, McFadden et al. attempt a detailed analysis of the source of meaning in the everyday lives of persons with dementia by employing Frankl's writings on the sources of meaning in life (2000, 67-86). And Close describes his practices of psychotherapy for patients with Major Depressive Disorder using Frankl's and Paul Tillich's theories (2000, 119-40). However, the previous researches into Frankl's theory are mainly on "meaning (in life)." It is quite right that the researchers pay special attention to the "meaning" in referring to Frankl's theory, since logotherapy's concept of man is based on three pillars, the freedom of will, the will to meaning, and the meaning of life (Frankl 1988, vii).

However, previous researches do not mention relational aspects of meaning in detail. Put differently, they do not adequately notice what connectedness or relationship in actualizing the meaning of life is really about in logotherapy. When James W. Ellor says, "Meaning is not an intra-psychic philosophical concept. Rather, it is a critical aspect of spirituality that points to humanity's fullest capacity for 'being"” $(2000,92)$, for sure, he just subtly states relational components of meaning, say, by referring to "capacity for "being," but not explicitly. As far as I have researched, when Frankl's three categories of meaning in life (creative values, experiential values, and attitudinal values) are discussed, their relational components are very often unnoticed.

The purpose of this article is to elucidate relational (connectedness) aspects of logotherapy rather than meaningfulness aspect and to formulate "coexistent values" as the fourth meaning in life. The plan of this paper is as follows: Chapter Two is a description of Frankl's three categories of meaning in life and points out the common elements of the fulfillment of three values are connectedness or relationship. In the next chapter, theoretical needs to formulate "coexist values" are discussed. In addition, what logotherapy really means is delineated in Frankl's own words. And in Chapter Four, what logotherapy is about is described and meaningfulness aspects and connectedness aspects of logotherapy are seen in Frankl's writings. Lastly, it is proposed that the concept of coexistent values of logotherapy, which has been insufficiently mentioned so far, has an advanced understanding of logotherapy, thus contributing to finding new values in logotherapy. 


\section{Frankl's Three Categories of Meaning in Life}

\subsection{Creative, Experiential, and Attitudinal Values-Connectedness or Relationship as Their Common Elements}

Frankl describes three ways of discovering meaning in life in logotherapy $(1984,133)$. That is, creative values, experiential values, and attitudinal values. Creative values are what one finds by creating a work or doing a deed. Experiential values are realized by experiencing something or encountering someone. Attitudinal values are what a person discovers by the attitude she/he takes toward unavoidable suffering $(1984,133)$. He delineates these three values in other expressions. Namely, he refers to creative values as "what he gives to the world in terms of creations," experiential values as "what he takes from the world in terms of encounters and experiences," and attitudinal values as "the stands he takes to his predicament in case he must face a fate which he cannot change" $(1988,70$, italic is original).

These three kinds of values points have something in common: connectedness or relationship. Creative values (e.g., an artistic masterpiece) show the worker's connectedness with the work accomplished. Experiential values also stand for the relationship between, say, a person and natural beauty. Frankl regards "experiencing another human being in his very uniqueness," that is, "experiencing love" as a kind of experiential value $(1984,134)$. Needless to say, there can be no love without connecting or connectedness. And he portrays attitudinal values by stating "He may turn a personal tragedy into a triumph" $(1984,170)$, as well. Then, we can say that attitudinal values indicate relationship between the sufferer and suffering itself.

Therefore, the core of Frankl's three values can be supposed to be connectedness or relationship. In other words, what Frankl calls meaning in life indicates manifestation of connectedness or relationship in the form of creations, experiences, and attitudes. Baumeister and Vohs say, "The essence of meaning is connection. Meaning can link two things even if they physically separate entities, such as if they belong to the same category, are owned by the same person, or are both used for a common goal" $(2002,608)$. This view is consistent with my view that the core of Frankl's three categories of meaning in life is connectedness. MacKinlay and Trevitt also state, “...it is through relationship that people with dementia are able to connect with others and find meaning in their very existence" $(2012,221)$. This statement also corresponds to my interpretation that the core of Frankl's three values in meaning in life is connectedness or relationship. They claim that people with dementia can connect with others and find meaning in life "through relationship."

\subsection{Theoretical Need to Formulate Coexistent Values and Their Definition}

My research into Frankl's writings has shown that he does not mention any cases where patients cannot fulfill their meaning by a deed or work they do, an experience or encounter they experience or an attitude they take toward suffering. And attitudinal values, which Frankl gives the highest worth in three types of meaning in life, are assumed to need some competence, or ego-strength. Frankl acknowledges this when he mentions a nurse suffering from a tumor. He says, "Her situation was really hopeless; nevertheless, I tried to explain to her that to work eight or ten hours per day is no great thing-many people can do that. But to be eager to work as she was, and so incapable of work, and yet not despair-that would be an achievement few could attain" (1986, xix). This statement of Frankl seems to strongly imply that attitudinal values such as the case of the nurse is not easy to attain, because the word "few" is used. 
Regarding his hellish experiences in Nazi concentration camps he experienced, he describes possibilities of aborted attitudinal values. He mentions attitudinal values by saying, "The way in which a man accepts his fate and all the suffering it entails, the way in which he takes up the cross, gives him ample opportunity-even under the most difficult circumstances-to add a deeper meaning. It may remain brave, dignified and unselfish" $(1984,88)$. It is obvious that these two sentences explain attitudinal values, though without using the concept. Following the above statement he continues, "Or in the bitter fight for self-preservation he may forget his human dignity and become no more than an animal" $(1984,88)$. That is, he witnessed one who could not find meaning in suffering, thus losing his human dignity.

So cannot human beings find their meaning in life without establishing Frankl's three categories of meaning in life? It can be affirmed that finding meaning in life by telling and sharing one's story with others occurs very often. For example, fulfilling one's creative values is precious and telling it as a story or past memory is also. Mackinlay and Trevitt who are RNs, provide examples of what dementia persons spoke of as most important to them and what brought meaning in a spiritual reminiscence work ${ }^{1}$. In the case of Claire who has dementia, she said, "Oh well I suppose getting married and having my daughter, things like that normally happen" $(2015,62)$. "Getting married and having my daughter" is fulfillment of creative values. To find an intimate partner, to create a new family, and to have a child is creative work. And to reminisce about it and to share it with others is very meaningful for Claire, because one of the questions to which she replied was "What gives greatest meaning to your life now" $(2015,62)$.

Claire's story-telling with others definitely is a fulfillment of her meaning in life, but does not seem to be suitable for any categories of Frankl's three meanings in life. Claire's talk with others is somewhat lacking in active or creative nature of what Frankl calls creative values. And telling one's life story and sharing it with others resembles, seemingly, what Frankl calls experiential values in that both are kinds of experience with someone or something. But such story-telling does not necessarily mean a passivity or receptivity which Frankl recognizes as the key feature of experiential values. Then, it is better not to identify meaningfulness actualized in spiritual reminiscence with experiential values. Of course, it is assumed that a participant of spiritual reminiscence takes something from other participants and gives them what she/he has taken from their life histories and experiences. In Clair's above-mentioned statement, she probably felt meaningfulness while telling an important part of her life story. And it is apparent that meaningfulness she feels with fellow members is not what Frankl calls attitudinal values, simply because she is not in suffering.

Accordingly, the need to formulate another avenue to fulfillment of meaning in life should be warranted. It should be proposed that "making connectedness" itself be values without any creative deeds, experiences of love and beauty, and brave attitudes in suffering, because the core of Frankl's three avenues to meaning in life is connectedness or relationship. Claire's meaning in life is actualized in coexistence with other participants. In the next chapter, the definition of "coexistent values" is established and their connotations in Frankl's writings of logotherapy are discussed.

\section{Coexistent Values}

\subsection{The Definition of Coexistent Values}

Coexistent values are defined as "values realized by having meaningful relationships or togetherness with others." in this paper. As stated above, it seems to be similar to what Frankl says experiential values, but previously said, it does not denote "passivity" or "receptiveness." 


\subsection{Coexistent Values Implicit in Frankl's Three Categories of Meaning in Life}

Previously stated, there is the concept of connectedness or relationship in three types of meaning in life that Frankl formulates. And it can be assumed that Frankl unknowingly recognized the importance of coexistent values. First of all, creative values, whether they are productive works, artistic masterpieces or sports, are fulfilled in connection with something or someone. When someone does good work in an organized system, coexistence with something or someone is always indicated. And if they are working with an artistic masterpiece, the artistic accomplishment will mean an embodiment of the artists' coexistence with the masterpieces. As to sports, it goes without saying that sports competition exists together with others: teammates, audience, and/or rivals. And it should be noted that Frankl tells us as follows: “...in any competition of sports man is really competing with himself. He is his own rival" (1978, 98, italic is original). Frankl's statement can be interpreted that an athlete can realize their creative values in the form of doing sports without teammates, audience, and rivals, because he employs the phrase competing with himself. A marathon training by oneself requires one to compete with oneself in order to improve, say, an Olympic record. Namely, creative values can be fulfilled just in coexistence with oneself.

Regarding experiential values, coexistent values can be found in Frankl's statements. When he mentions a young man who had long since had to abandon his profession due to his handicapped ability caused by paralysis, he says,

There was for him therefore no longer any chance to realize creative values. But even in this state the realm of experiential values remained open to him. He passed the time in stimulating conversation with other patients - entertaining them also, encouraging and consoling them. He devoted himself to reading good books, and especially to listening to good music on the radio. $(1986,45-46)$

The patient's experiential values were realized in relation to something other: other patients, good books, and good music. That is, they were fulfilled in stimulating conversation with other patients - entertaining them also, encouraging, and consoling them. And reading books is actualized by the readers' involvement into the books. Listening music can be meaningful when the listener is really engaged or connected with music. The realization of coexistent values can be found in the realm of experiential values.

Coexistence values can be found in the realization of attitudinal value as well. Frankl continues,

while before he had been compelled to withdraw from creative values to experiential values, he was forced now to make the further retreat to attitudinal values. How else shall we interpret his behavior-for he now set himself the role of advisor to his fellow sufferers, and in every way strove to be an exemplar to them. He bore his own suffering bravely. The day before his death - which he foresaw - he knew that the doctor on duty had been ordered to give him an injection of morphine at night. What did the sick man do? When the doctor came to see him on his afternoon round, the patient asked him to give him the injection in the evening - so that the doctor would not have to interrupt his night's rest just on his account. $(1986,46)$

In this story of "attitudinal values," there is a realization of coexistent values. The patient's attitudinal values were actualized in the context of his coexistence with his doctor. The subject who demonstrated his attitudinal values is the patient himself, but it was fulfilled in coexistence with his doctor. The patient's attitudinal values needed the other to be realized. That is, they were fulfilled by being combined with "coexistent values." As a person is really competing with her-himself in the sports, she or he is trying to take the right attitude toward her-himself in attaining her or his attitudinal values. 
Thus, it can be said that coexistent values are inherent in creative, experiential, and attitudinal values.

\section{Coexistent Values as the Core of Logotherapy}

\subsection{What Is Logotherapy?}

Frankl describes how to discover the meaning in life in three different ways as logotherapy $(1984,133)$. The three ways have previously been described. And he says, "By way of a deliberate oversimplification, one could define logotherapy by the literal translation as healing through meaning" (1988, 9), "logotherapy's concept of man is based on three pillars, the freedom of will, the will to meaning, and the meaning of life" (1988, vii). And Frankl defines will to meaning as follows. "What I call the will to meaning could be defined as the basic striving of man to find and fulfill meaning and purpose" $(1988,35)$. Next two statements are supposed to be crucial to understand what logotherapy is really about. "Will to meaning is the guiding principle of the mature adult" $(1988,41)$. "Logotherapy aims to unlock the will to meaning and to assist the patient in seeing a meaning in his life" $(1985,131)$.

Taking those explanations of logotherapy into account, it goes without saying that logotherapy's most fundamental concept is meaning. Logos in Greek is meaning, and two of the three pillars do concern meaning. Additionally, the last statement on logotherapy above, "Logotherapy aims to unlock the will to meaning and to assist the patient in seeing a meaning in his life" can be justified as "logotherapy's purpose is to help patients find meaning in life" because of its very similarities of to assist the patient in seeing a meaning in life and [logotherapy's purpose is] to help patients find meaning in life. Furthermore, logotherapy's purpose is to help patients find meaning in life is almost synonymous for "healing through meaning" because of the likeness between "to help" and "healing."

But the relational or coexistent aspects of logotherapy are indicated very little in Frankl's portrayal of it. Those aspects of logotherapy should be noticed, because too much attention to meaning of logotherapy without taking notice of relational aspects would lose sight of its coexistent aspect of it. After all, logotherapy is a therapy and a therapy cannot be established without making connectedness between the client and the therapist. This view is further amplified in the statement that, "The essence of meaning is connection" (Baumeister \& Vohs 2002, 608). Moreover, Cunningham offers a similar view of mine that the core of meaning is connectedness or relationship. He describes the meaning of cancer by stating,

The meaning of the event is its relationship to other events, how it fits into the web of associated happenings./Cancer is also an event or process, albeit a slow-motion one. It, too, must have meaning in this sense; that is, it is inextricably related to many other events in the patient, in his or her environment, and in the world. The meaning of cancer, according to this view, derives from these relationships. All events have such meaning; life has meaning. If we deny meaning to cancer, we are denying it to our lives, and to everything else. (1992, 132, italic is original)

Cunningham's view can be summarized into three points: (1) The meaning of the event is its relationship to other events, (2) cancer is also an event or process, and (3) the meaning of cancer derives from its relationships to other events. Moreover, that the meaning of the event derives from its relationship to other events does indicate meaning and relationship are intimately interconnected. The recognition of the connectedness or relationship in the concept of meaning could lead to hypothesize that careful inquiry into logotherapy will reveal connectedness or relationship or its implication. 


\subsection{Meaningfulness and Connectedness as Two Crucial Components of Logotherapy}

\subsubsection{Meaningfulness Aspects of Logotherapy}

As it is indicated in 4.1., logotherapy's most essential mainstay is meaning. Frankl states it in all his writings, such as: "Logotherapy signifies a psychotherapy that is oriented toward meaning and that reorients the patients toward meaning" $(2010,81)$, "Logotherapy aims to unlock the will to meaning and assist the patient in seeing a meaning in his life" $(1985,131)$.

It should be noted that meaningfulness and connectedness are intimately linked to each other. It can be shown in 3.2. However, there are almost no previous studies focusing on the connectedness aspects of logotherapy. Therefore, it would be logical and reasonable attempt to pay special attention to connectedness aspects of logotherapy. It is expected that it will contribute to shed new light on the structure of logotherapy.

\subsubsection{Connectedness Aspects of Logotherapy}

In contrast to meaningfulness aspects of logotherapy, Frankl makes little reference to its connectedness aspects. This, however, does not indicate he is not aware of what connectedness is all about. The following statements are his indications of the importance of connectedness in logotherapy

First of all, he says, "Man is reaching out for, and actually reaching, finally attaining, the world—a world, that is, which is replete with other beings to encounter, and meaning to fulfill" $(1988,31)$. In this sentence, Frankl refers to the connectedness with the world by stating "reaching out for, and actually reaching, finally attaining," because these three present participles show relationship. That is, when one reaches out for something, it means they takes initiative "to try and contact or connect with someone to get help, guidance, comfort, or support" (The Free Dictionary's Idiom's Dictionary, 2018). And "attaining" indicates "to succeed in getting something, usually after a lot of effort" and "reach a particular age, level or condition" (Oxford Advanced Learners Dictionary, 7th ed., 2005, 95), so it is also an indication of connecting or relating. If one succeeds in getting something, she or he manages to establish the relationship with something they has got.

Next, Frankl states as follows: "...this is not to say that we logotherapists overate the importance of techniques. One has long ago come to realize that what matters in therapy is not techniques but rather the human relationship between doctor and patient, or the personal and existential encounter" $(1988,6)$.

It can be found that Frankl's primary concern as a logotherapist is to make the connectedness in his reference to "the human relationship between doctor and patient, or the personal and existential encounter." And Frankl shows connectedness aspects of logotherapy when he says, "It is a tenet of logotherapy that the humanness of man is grounded in his sense of responsibility...Man is responsible for fulfilling the meaning of his life. Being human means responding to life situations, replying to the questions they ask" $(1985,121)$.

It can be construed that "responding to life situations" denotes one's connectedness with "life situation" and "replying to the questions they ask" is realized in one's relation to the questions. Responding to life situations, say, an abortive attempt to accomplish required tasks, probably could mean one's engagement in making up for the unmet tasks. In this circumstance, there would be one's connectedness with the unmet tasks.

In addition, Frankl's concept "self-transcendence" needs to be clarified. It is the very concept indicative of coexistent values. Frankl tells of self-transcendence, stating “...denoting the fact that being human basically means relating, and being directed, to something other than himself" (1978, 66). Being human, say, showing kindness, of course, means "relating, and being directed, to something other than himself" in that those who are kind to others are trying to relate to the receiver of kindness. Therefore, values realized by having meaningful 
relationships or togetherness with others or coexistent values are inherent in self-transcendence, because when values of kindness are actualized between kindness-giver and kindness-receiver, both are together with each other.

Frankl touches on "coexistent values" in relation to encounters. He says, "True encounter is a mode of coexistence that is open to the logos, allowing the partners to transcend themselves toward the logos, and even promoting such mutual transcendence" (1978, 66, italic is mine). Human beings share their stories, experiences, presence, our time, and/or our opportunities when a true encounter is achieved. Of course, encounter involves love and vice versa. When love is actualized as a kind of experiential values, an encounter between the lover and the beloved is definitely achieved. When Frankl says, "...coexistence is open to the logos, allowing the partners to transcend themselves toward the logos, and even promoting such mutual transcendence," it definitely signifies "having meaningful relationship or togetherness with others." Because, as I have said , in Frankl's every avenue to finding meaning in life, the idea of connectedness can be found and connectedness always involves coexistence. And "coexistence is open to logos" amounts to "coexistence is open to meaning" due to the fact that logos in Greek means "meaning."

Furthermore, he speaks of love as regard to self-transcendence. "Man transcends himself either toward another human being or toward meaning. Love, I would say, is that capacity which enables him to grasp the other human being in his very uniqueness" (1988, 18-19).

In 2.1., love is described as an example of experiential values actualized in passivity. And he says,

One should not overlook nor forget, however, that self-transcendence means reaching out not only for a meaning to fulfill but also another human being, another person, to love. To be sure, love goes beyond encounter inasmuch as the latter moves on the human, the former on the personal level. Encounter in the broader sense of the word makes us realize the humanness of the partner, whereas loving him shows us more-his essential uniqueness. This uniqueness is the constitutive characteristic of personhood. As to the self-transcendence, however, it is equally implied whether man transcends himself by meaning fulfillment or loving encounter: in the first case, an impersonal logos is involved; in the second, a personal logos—an incarnated logos, so to speak. (1978, 66-67)

From what Frankl means by "self-transcendence" above, it can be supposed that it points to connectedness or relationship with something beyond oneself. By Frankl's saying "Being human is directed to something other than itself" $(1988,50)$, he refers to a human being's aim to connect with others beyond her/himself in my view. Because judging from the dictionary definition of "to direct" or "to aim something in a particular direction or particular person" (Oxford Advanced Learner's Dictionary, 7th ed., 2005, 483), "directed to something" strongly implies connectedness with something.

Therefore, though not explicitly, connectedness aspects of logotherapy can be seen, in particular in the realization of love and encounter in Frankl's theory. As described above, meaningfulness aspects of logotherapy are very manifest in Frankl's writings. Talking of Frankl, almost all of researchers and clinicians call attention to his meaningfulness aspects of logotherapy. In this section, connectedness aspects of logotherapy have been shown. Next, what the aspects do contributes to shedding new light on new understandings of Frankl's thoughts.

\section{Conclusion}

Frankl's three kinds of realizations of meaning in life are indispensable tools to understand what "meaning" is all about when referring to human being's meaning in life. And as stated above, careful analysis of Frankl's 
description of logotherapy shows connectedness aspects of the concept, in addition to its meaningfulness. However, theorists and researchers, including Frankl, are very less inclined to refer to connectedness aspects of logotherapy. On the other hand, attention should be paid to the connectedness aspects of logotherapy, because first of all, as stated in section 4.2.2., highlighting connectedness aspects could shed new light on logotherapy, that is, to see logotherapy from quite a different point of view from other theorists. Additionally, pointing out logotherapy's connectedness aspects would also show interconnectedness of meaningfulness and connectedness.

"Spiritual reminiscence" by MacKinlay and Trevitt (2015), stated previously, consists of six main weekly themes. Its first week theme is "life-in meaning" (59-64). Their statement "You will notice that relationship is commonly where these people with dementia find meaning" (62) should be noted, because it shows the very interconnectedness of meaningfulness with connectedness. And the main theme of the second week of "spiritual reminiscence" is "relationship, isolation and connecting" (65-71). They write, "For many older people, with or without dementia, relationship is what provides most meaning in life" (65).

The concept of connectedness has been found in each of Frankl's three avenues to meaning in life, as noted in 2.1. And not only in logotherapy but other professional helping methods, connectedness or relationship is of paramount importance. For example, as to both casework and nursing, no one denies the client-therapist relationship really matters as the essential elements in helping their clients. A famous and influential Catholic caseworker, Felix P. Biestek states clearly, "A good relationship is necessary not only for the perfection, but also for the essence, of the casework service in every setting" $(1957,19)$. Burkhardt and Nagai-Jacobson from their standpoints of holistic nursing, say, "The spiritual journey is more a search for right relationship than it is a search for right answers. As humans, we are social beings whose very survival is linked to the ways we connect with others" $(2002,265)$. After all, both therapy and care cannot be possible to be practiced without making the connectedness or relationship.

And regarding "self-transcendence," which is the kernel of Frankl's thoughts, the idea of connectedness or relationship has been found after a careful consideration of the core concept. Both love and encounter, which are manifestation of the self-transcendence as mentioned above, are not realized without making connectedness. But other researchers' as well as Frankl's writings tend not to pay careful attention to connectedness aspects of Frankl's idea of self-transcendence. Frankl asserts, "Human existence is not authentic unless it is lived in terms of self-transcendence" $(1988,52)$ and, "Human beings are transcending themselves toward meanings which are something other than themselves, more than mere projections of these selves. The essentially self-transcendent quality of human existence renders man a being reaching out beyond himself' (Frankl 1988, 8, italic is original).

But these statements of Frankl tell us that his sense of self-transcendence does not explicitly manifest relational or connectedness aspects of logotherapy. The phrase "a being reaching out beyond himself" indicates connectedness aspects of logotherapy, but just implicitly. As previously said, "reach out for" denotes "to try and contact or connect with someone to get help, guidance, comfort, or support" (The Free Dictionary's Idiom's Dictionary, 2018). And Frankl adds two words "beyond himself" to the idiom. So it is supposed that by self-transcendence, one could infer that Frankl refers to connectedness to "something beyond oneself" or "something other than oneself." He means everyday relationships as well as higher power by "something beyond oneself" or "something other than oneself." Although he does not employ "connectedness" or "relationship," which clearly shows relating regarding "self-transcendence," it was shown in this article the terms are related to the concept. 
Treating and caring for people with dementia is a challengingly crucial task of our time. As seen in 2.2, they can find meaning in life without turning to any categories of meaning in life proposed by Frankl. They realize their meaning in life just by "having meaningful relationships or togetherness with others" through sharing their life-stories with others. Many of them cannot exercise particular abilities required to fulfill Frankl's three types of meaning in life. As is suggested in 2.2, it is assumed that some people could not realize their meanings in life by creative works and/or deeds, experiences of love and encounters, and brave attitudes in suffering.

It is expected that this paper will contribute to illuminating the connectedness aspects of logotherapy and finding the unnoticed aspects of it. Furthermore, recognition of connectedness aspects of logotherapy which have been discussed very inadequately thus far could confirm that the concept of meaning is intimately linked to the concept of connection. The author is not engaged in clinical or social service practice now and cannot present his opinions based on practical experiences. However, this study is anticipated to attract health care professionals' as well as theorists' attention by Frankl's hidden legacy called connectedness aspects of logotherapy.

\section{Notes}

1. "Spiritual reminiscence is a way of telling a life story with an emphasis on what gives meaning to life, what have given joy or brought sadness" (Mackinlay \& Trevitt 2015, 46).

\section{Works Cited}

Baumeister, R. F., \& Vohs, K. D. "The Pursuit of Meaningfulness in Life.” Eds. Snyder, C. R., \& Lopez, S. J. Handbook of Positive Psychology. New York: Oxford University Press, 2002. 608.

Biestek, P. F. The Casework Relationship. Chicago: Loyola University Press, 1957.

Burkhardt, M. A., \& Nagai-Jacobson, M. G. Spirituality Living Our Connectedness. Albany: DELMAR* Thomson Learning, 2002.

Close, R. A. "Logotherapy and Adult Major Depression: Psychotheological Dimensions in Diagnosing the Disorder." Ed. M. A. Kimble. Viktor Frankl's Contribution to Spirituality and Aging. Binghamton, New York: The Haworth Press, 2000. 119-40.

Cunningham, A. J. The Healing Journey Overcoming the Crisis of Cancer. Toronto: Key Porter Books Limited, 1992.

Frankl, V. E. The Feeling of Meaninglessness. A Challenge to Psychotherapy and Philosophy. Milwaukee: Marquette University Press, 2010.

---. The Will to Meaning Foundations and Application of Logotherapy. New York: Meridian Book, 1988.

---. Man's Search for Meaning. New York: Pocket Books, 1984.

---. The Doctor and the Soul From Psychotherapy to Logotherapy. New York: Vintage Books, 1986.

---. The Unheard Cry for Meaning Psychotherapy \& Humanism. New York: A Touchstone Book, 1978.

---. The Unconscious God. New York: Pocket Books, 1975.

Mackinlay, E., \& Trevitt, C. Facilitating Spiritual Reminiscence for People With Dementia. London: Jessica Kingsley Publishers, 2015.

McFadden, S. H., Ingram, M., \& Baldauf, C. “Actions, Feelings, and Values: Foundation of Meaning and Personhood in Dementia." Ed. Melvin A. Kimble. Viktor Frankl's Contribution to Spirituality and Aging. Binghamton, New York: The Haworth Press, 2000. 67-86.

Oxford Advanced Learners Dictionary (7th ed.). Oxford: Oxford University Press, 2005.

Sulmasy, D. P. “A Biopsychosocial-Spiritual Model for the Care of Patients at the End of Life.” The Gerontologist 42, Special Issue III (2002): 24-33.

The Free Dictionary'Idiom's Dictionary. July 3, 2018. <https://idioms.thefreedictionary.com/reach+out+for>. 